\title{
Refinamento paramétrico de Rietveld aliado a dados de monitoramento in-situ da hidratação do gesso de construção por DRXP
}

\author{
H. C. F. Cordon ${ }^{\mathrm{a}, \mathrm{b}}$, F. F. Ferreira ${ }^{\mathrm{a}}$. \\ ${ }^{a}$ Centro de Ciências Naturais e Humanas, Universidade Federal do ABC, Santo André, Brasil. \\ ${ }^{b}$ Instituto Mauá de Tecnologia, São Caetano do Sul, Brasil.
}

A utilização do gesso na construção civil vem crescendo por fatores como baixo custo do material, disponibilidade e soluções construtivas mais rápidas. Por apresentar rápido endurecimento, o desperdício de gesso é um problema sério, uma vez que sua disposição em aterros pode gerar contaminação do solo e da água, além da formação de gases tóxicos e inflamáveis. Por outro lado, sua reciclagem é atrativa, através da calcinação do resíduo em temperaturas amenas $\left(140^{\circ} \mathrm{C}\right.$ a $\left.160^{\circ} \mathrm{C}\right){ }^{[1]}$. Entretanto, as características do material reciclado devem ser bem avaliadas para que este processo se torne corriqueiro. Este trabalho tem como objetivo avaliar o impacto da reciclagem na reatividade do gesso. Para tanto, medidas de DRXP in-situ, para monitoramento da hidratação do gesso, serviram de base para os refinamentos sequencial e paramétrico em função do tempo, o que permitiu avaliar a reatividade do gesso reciclado em comparação com a amostra comercial.

Foram preparadas pastas de gesso com uma amostra comercial e reciclada obtida a partir da moagem e calcinação a $160{ }^{\circ} \mathrm{C}$ do gesso comercial hidratado, com relação água/gesso $(\mathrm{a} / \mathrm{g})$ igual a $60 \%$. Os dados de DRXP foram coletados à temperatura ambiente em um equipamento da marca Stoe ${ }^{\circledR}$, modelo STADI-P, com radiação monocromática $\lambda=1,54056 \AA\left(\mathrm{CuK} \alpha_{1}\right)$ operando a $40 \mathrm{kV}$ e $40 \mathrm{~mA}$, na geometria de transmissão, com as amostras acondicionadas em um porta-amostra contendo duas folhas de acetato-celulose, mantido em rotação durante a aquisição de dados. As intensidades difratadas foram coletadas por um detector linear, Mythen $1 \mathrm{~K}$, na faixa fixa de $10^{\circ}$ a $28,9^{\circ}$, com tempo de integração de $300 \mathrm{~s}$.

Com os dados de DRXP coletados durante a hidratação das amostras realizou-se o refinamento sequencial de Rietveld para a determinação das frações em massa dos compostos a base de sulfato de cálcio (anidrita, bassanita e gipsita) em função do tempo (Figura 1). Para cada amostra, foram refinados 11 parâmetros de rede ( $a, b, c$ e $\beta$ das fases gipsita e bassanita e a, b e c da fase anidrita), totalizando 88 parâmetros refinados na amostra de gesso comercial e 66 parâmetros refinados na amostra de gesso reciclado. Observa-se que à medida que o teor de bassanita diminui, o teor de gipsita aumenta na mesma proporção, porém o comportamento da amostra comercial e reciclada é bastante distinto. Para a amostra comercial, a fase predominante no início é a bassanita, sendo que a fase gipsita só começa a aparecer a partir de 13 minutos. Entretanto, logo na primeira medida da amostra reciclada o teor de gipsita é de praticamente $50 \%$, comprovando que a reação da bassanita com a água é instantânea, o que pode ser explicado pela maior área superficial específica da amostra de gesso reciclado, que foi obtida pelo método de $\mathrm{BET}^{[2]}$, cujos valores encontrados foram $2,45 \mathrm{~m}^{2} \cdot \mathrm{g}^{-1}$ para a amostra comercial e $3,46 \mathrm{~m}^{2} \cdot \mathrm{g}^{-1}$ para a reciclada. Para o tempo total do experimento, o teor de anidrita permaneceu praticamente constante nos dois casos, indicando que esta é uma fase de reatividade lenta. Com o intuito de melhorar o tratamento dos dados, aplicou-se o método de refinamento paramétrico de Rietveld ${ }^{[3]}$, que é uma ferramenta importante para a análise e tratamento dos dados de DRXP coletados em função do tempo, inclusive quando os dados utilizados não apresentam grande resolução, aos dados de difração coletados durante a hidratação das amostras de gesso comercial e reciclado (Figura 1) a partir da parametrização dos 11 parâmetros de rede das celas unitárias dos compostos (anidrita, bassanita e gipsita). 


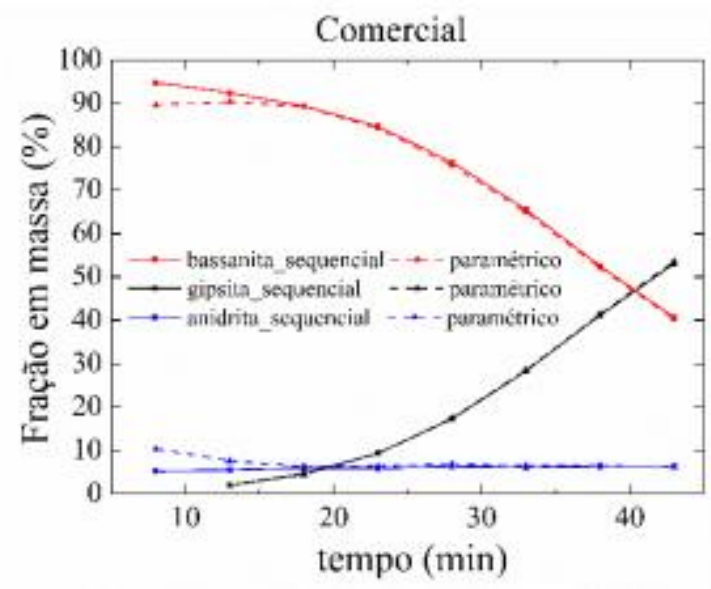

(a)

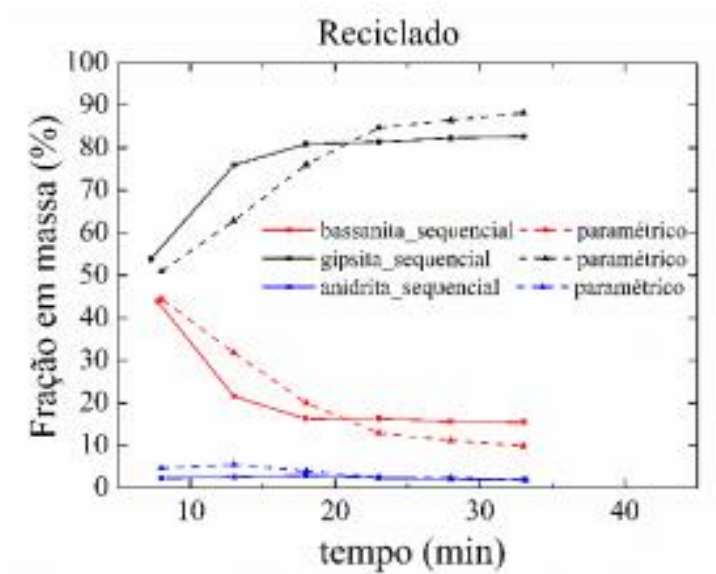

(b)

Figura 1: Frações em massa dos compostos a base de sulfato de cálcio (anidrita - símbolos azuis; bassanita - símbolos pretos; e gipsita - símbolos vermelhos) em função do tempo de hidratação das amostras de gesso comercial (a) e reciclado (b) obtidas pelos refinamentos sequencial - linhas contínuas - e paramétrico - linhas tracejadas - de Rietveld.

O estudo da hidratação do gesso com o auxílio do monitoramento in-situ realizado com medidas de DRXP em função do tempo permitiu concluir que há formação instantânea de gipsita assim que o material reciclado entra em contato com a água. Estes dados também confirmam que a formação dos compostos hidratados é muito mais rápida para a amostra de gesso reciclado por conta da maior área superficial específica.

[1] PINHEIRO, S. M. M. Gesso reciclado: Avaliação de propriedades para uso em componentes. Tese de doutorado. Universidade Estadual de Campinas, 2011.

[2] BRUNAUER, STEPHEN; EMMET, P. H.; TELLER, E. Adsorption of Gases in Multimolecular Layers. Journal of the American Chemical Society, v. 60, n. 2, p. 309-319, 1938.

[3] EVANS, J. S. O. Parametric Rietveld refinement. Accuracy in Powder Diffraction IV - APD IV. Anais...Gaithersburg: $2013 \quad$ Disponível em: <https://www.nist.gov/sites/default/files/documents/mml/3-1_JEvans_APD_IV.pdf>. Acesso em: 9 jun. 2017.

Agradecimentos: Laboratório de Cristalografia e Caracterização Estrutural de Materiais (LCCEM) da Universidade Federal do ABC e Laboratório de Microestrutura e Ecoeficiência de Materiais de Construção (LME) da Escola Politécnica da USP. 